\title{
O PAPEL DA MULTIMODALIDADE NA AQUISIÇÃO DA LINGUAGEM DE CRIANÇAS PREMATURAS
}

\author{
THE ROLE OF MULTIMODALITY IN THE ACQUISITION OF PREMATURE \\ CHILDREN'S LANGUAGE
}

\author{
Divany Guedes Pereira da Cunha ${ }^{1}$ \\ Fernanda Aparecida Ferreira de Freitas ${ }^{2}$ \\ Julyane Feitosa Coêlho ${ }^{3}$
}

\begin{abstract}
RESUMO: Esse artigo tem como objetivo apresentar considerações teóricas sobre o desenvolvimento da linguagem de crianças prematuras numa perspectiva multimodal. Os procedimentos metodológicos envolveram uma breve revisão da literatura de artigos científicos indexados em bases de dados nacionais e internacionais, livros, dissertações e teses sobre a temática pesquisada. Após a busca, leitura e seleção dos textos, os resultados foram divididos em: 1- Prematuridade, 2- Aquisição da Linguagem na perspectiva multimodal e 3- Linguagem, multimodalidade e prematuridade. Nas bases de dados pesquisadas foi observada a escassez de estudos que discutissem o desempenho linguístico de crianças prematuras, a partir da multimodalidade. Os estudos analisados demonstraram que as crianças nascidas mais precocemente tiveram um desempenho pior na linguagem do que as prematuras moderadas e tardias (PUTNICH et al., 2017), além de lenta aquisição na produção de gestos (SANSAVINI et al., 2011), atrasos no léxico, pragmática, sendo os atrasos na fonologia e gramática menos difusos (GUARINI et al., 2016). Observou-se um risco de desenvolvimento linguístico menos favorável nos prematuros (SCHUYMER et al., 2011) e que o conhecimento era transmitido com menos frequência através da modalidade gestual falada bimodal nestas crianças (SANSAVINI et al., 2015). Podendo-se destacar também o papel dos gestos como um preditor significativo para habilidades de linguagem em crianças prematuras (STOLT et al., 2016), associando-se positivamente ao desenvolvimento de habilidades lexicais e morfossintáticas (SUTTORA, SALERNI, 2012). Percebe-se a relação existente entre aquisição da linguagem e multimodalidade em crianças prematuras, sendo relevantes as pesquisas voltadas para essa temática, assumindo a indissociabilidade envolvida na matriz gesto-fala. Diante do exposto, sugere-se mais estudos voltados para os aspectos multimodais e linguísticos da referida população, beneficiando o entendimento de como eles se revelam ou, até mesmo, de como podem ser criadas estratégias de ampliação da comunicação, considerando os variados contextos de circulação da Língua com vistas à interação.
\end{abstract}

Palavras-chave: Aquisição da Linguagem, Prematuro, Multimodalidade.

ABSTRACT: This article aims to present theoretical considerations about the language development of premature children in a multimodal perspective. The methodological procedures involved a brief review of the literature of scientific articles indexed in national and international databases, books, dissertations and theses on the researched theme. After searching, reading and selecting the texts, the results were divided into: 1- Prematurity, 2- Language Acquisition in the multimodal perspective and 3- Language, multimodality and prematurity. In the searched databases, there was a scarcity of studies that discussed the linguistic performance of premature children, based on multimodality. The studies analyzed showed that children born earlier performed worse in language than moderate and late preterm infants (PUTNICH et al., 2017), as well as slow acquisition in gesture production (SANSAVINI et al., 2011), delays in lexicon, pragmatic, with delays in phonology and grammar less diffuse (GUARINI et al., 2016). There was a less favorable risk of language development in preterm infants (SCHUYMER et al., 2011)., And that knowledge was transmitted less frequently through bimodal spoken gestural modality in these children (SANSAVINI et al., 2015). We can also highlight the role of gestures as a significant predictor of language skills in premature children (STOLT et al., 2016). Positively associated with the development of lexical and morphosyntactic skills (SUTTORA, SALERNI, 2012). The relation between language acquisition and multimodality in premature children is observed, being relevant the research focused on this theme, assuming the inseparability involved in the gesture-speech matrix. Given the above, it is suggested further studies focused on the multimodal and linguistic aspects of this population, benefiting the understanding of how they reveal themselves or even how strategies for broadening communication can be created, considering the various contexts of circulation. of Language with a view to interaction.

\footnotetext{
${ }^{1}$ Doutoranda em Linguística pela Universidade Federal da Paraíba-UFPB. E-mail: divany.pereira@hotmail.com

2 Doutoranda em Linguística pela Universidade Federal da Paraíba-UFPB. E-mail:

fernandaaparecida@hotmail.com

${ }^{3}$ Doutoranda em Linguística pela Universidade Federal da Paraíba-UFPB. E-mail: julyanecoelho@hotmail.com
} 
Volume 14 - Número 2 - ago/dez de 2019

Keywords: Language Acquisition, Premature, Multimodality

\section{Introdução}

O estudo da aquisição da linguagem representa uma busca contínua em entender o modo como um indivíduo passa de não-falante a falante de sua língua materna ou de uma segunda língua. Ao longo do tempo, pesquisadores de diversas áreas procuram compreender de que forma se dá esse processo singular que permite o desenvolvimento da capacidade linguísticocomunicativa no homem. A criança com desenvolvimento considerado típico, durante o processo de aquisição, busca nos estímulos aos quais é exposta, pistas fonético-fonológicas que lhe ofereçam informações sobre as estruturas de funcionamento da língua, como por exemplo a segmentação de palavras, de sílabas, de sintagmas, de enunciados. Com a passagem do tempo, maior exposição e contato com a língua, é proporcionado a criança um conhecimento mais refinado e a mesma começa a fazer segmentações mais aperfeiçoadas, a construir estruturas mais complexas, assim como, posteriormente, passa a expressar-se metalinguisticamente sobre esse conhecimento (LORANDI, CRUZ, SCHERER, 2011).

A Aquisição da Linguagem se constitui em um campo de conhecimento híbrido, que se utiliza de contribuições e interfaces com diversas áreas, buscando explicar a partir de teorias como ocorre o fenômeno da aquisição de uma língua, considerando-o segundo diversas perspectivas de análise, a depender dos aspectos de interesse central. Nesse sentido, ganham destaque os estudos que se propõem a investigar o processo de aquisição e desenvolvimento de linguagem em condições atípicas, associado a patologias ou a fatores que influenciem o percurso natural do desenvolvimento, proporcionando um maior conhecimento e clareza, como também contribuindo ao fornecer subsídios para a prática clínica na área. Diante disso, uma importante temática a ser considerada é a da prematuridade, por estar associada a uma série de repercussões na vida da criança, desde o início do desenvolvimento, podendo interferir também no desenvolvimento linguístico.

A medicina nas suas diversas áreas, incluindo a obstetrícia, vem apresentando inúmeros avanços objetivando melhorar o cenário de saúde no Brasil. No entanto a ocorrência de partos prematuros se configura como um dos grandes problemas de saúde pública, em virtude da morbidade e da mortalidade neonatal que ocasiona (ALMEIDA et al., 2012).

O recém-nascido prematuro pode ser definido como aquele que nasce com idade gestacional inferior a 37 semanas completas de gestação e como criança baixo peso, toda aquela com peso do nascimento inferior a 2500g (BRASIL, 2011). A Organização Mundial da Saúde (OMS) refere que os prematuros podem ser classificados em três subcategorias: extremamente prematuro (menos de 28 semanas) muito prematuro ( 28 a 32 semanas); prematuro moderado a tardio (32 a 37 semanas). Presume-se que 15 milhões de bebês nascem cedo demais a cada ano. Aproximadamente 1 milhão de crianças morrem a cada ano devido a complicações do parto prematuro, as que sobrevivem podem encarar uma vida inteira de deficiência, incluindo dificuldades de aprendizagem e problemas visuais e auditivos (OMS, 2013).

É importante explanar que o recém-nascido prematuro não apresenta o funcionamento dos órgãos prontos para a vida extrauterina, necessitando de cuidados intensivos e equipe multiprofissional para garantir sua sobrevivência. Portanto, a preocupação com essas crianças não deve ser apenas com a sobrevivência, mas também com o desenvolvimento global incluindo o motor, linguístico, multimodal, cognitivo, comportamental, social e de aprendizagem.

Mello e Meio (2003) afirmam que os bebes prematuros, principalmente os de peso inferior a 1.500 gramas ao nascimento, são considerados grupo de crianças de risco, pois tem maiores chances de apresentar algum problema em seu desenvolvimento, crescimento ou comprometimento clínico. Os autores ainda enfatizam a importância de um acompanhamento 
particularizado para que possíveis alterações sejam identificadas de forma precoce, viabilizando assim, intervenções de forma célere com o objetivo de minimizar possíveis sequelas.

Viana, Andrade e Lopes (2014) reforçam que as crianças com histórico de prematuridade estão sujeitas a apresentar alto risco para alterações do desenvolvimento cognitivo e, consequentemente, desenvolvimento de linguagem.

A aquisição da linguagem pode ser considerada no âmbito da Multimodalidade, ao reconhecer que a linguagem verbal e a não-verbal estão inseridas em uma relação em que ambas podem modificar e/ou reconstruir significados. Considerando que o funcionamento da língua é sempre multimodal, parte-se da premissa de que gesto e fala são constitutivos de um único sistema linguístico, não podendo ser dissociados. Nessa perspectiva, gesto e fala se encontram integrados, constituindo-se como elementos de uma mesma matriz de funcionamento linguístico-cognitivo, matriz única de produção e significação, estando mesclados no sistema da linguagem. A partir de um funcionamento linguístico multimodal, assume-se que gesto e fala constituem as cenas de atenção conjunta e formam o todo discursivo. Nessa perspectiva, o discurso se constrói a partir da relação estabelecida entre gesto e fala como matriz de significação (FONTE, CAVALCANTE, 2016; CAVALCANTE, 2018).

Desta forma, o presente trabalho busca considerar os estudos e as análises do processo de aquisição de linguagem em crianças prematuras ressaltando a presença indissociável da multimodalidade.

\section{Método}

Para a realização do estudo utilizou-se revisão teórica sobre as temáticas multimodalidade, linguagem e prematuridade, sendo viabilizado a partir de artigos científicos indexados em bases de dados nacionais, internacionais, livros, dissertações e teses.

O levantamento dos artigos foi realizado por meio de consulta ao Portal da Biblioteca Virtual de Saúde (BVS) incluindo as bases de dados MEDLINE (Medical Literature Analysis and Retrieval System Online) e LILACS (Literatura Latino-Americana e do Caribe em Ciências da Saúde), como também por busca na base de dados PubMed. Os livros, dissertações e teses foram considerados a partir da literatura disponível na área e consulta a repositórios de teses e dissertações disponíveis online.

A busca do material ocorreu nos meses de junho e outubro de 2019, considerando as palavras-chave: Multimodalidade, Aquisição da linguagem e Prematuro. Como também os descritores em inglês: Infant, Premature; Language acquisition; Multimodality; e Gestuality.

Para constituir a amostra foram selecionados critérios de inclusão, tais como: textos no formato de artigos científicos nos idiomas português ou inglês com texto completo disponível, textos de capítulos de livros, dissertações e teses nas temáticas abordadas.

\section{Discussão e Resultados}

\subsection{Prematuridade}

O nascimento prematuro é decorrente de circunstâncias diversas e imprevisíveis, em todos os lugares e classes sociais (RAMOS, CUMAN, 2009). A prematuridade e o baixo peso ao nascer são fatores determinantes para diversas intercorrências, como infecções, hospitalizações prolongadas, déficit de desenvolvimentos motor e intelectual, instabilidades emocionais e até mesmo mortalidade neonatal. Essas duas últimas condições merecem especial atenção, no sentido de preveni-las e, dessa forma, evitar complicações (PESSOA et al., 2015).

Dentre os comprometimentos associados à prematuridade ressalta-se a displasia broncopulmonar (DBP) que acomete o sistema respiratório. A mesma consiste em uma doença 
adquirida em recém-nascidos prematuros de extremo baixo peso, com baixa idade gestacional, e que foram expostos a toxicidade do oxigênio por mais de 28 dias de vida (VALÉRIO, GARDENGHI, 2016). Estudos mostram a relação entre a DBP e desenvolvimento cognitivo no qual avaliou-se 112 crianças através da escala de Wechsler e os escores médios foram comparados entre crianças com e sem Displasia broncopulmonar. O resultado da referida pesquisa mostrou que não houve diferenças do quociente de inteligência em escala total, do quociente de inteligência verbal, do quociente de inteligência de desempenho e dos domínios da linguagem oral. $\mathrm{O}$ quociente de velocidade de processamento foi o único que apresentou diferença significativa entre os dois grupos (MELLO, REIS, SILVA, 2017).

Os fatores associados à prematuridade podem interferir no desenvolvimento global infantil, incluindo motor, sensorial, cognição, aprendizagem e linguagem. Os primeiros meses de vida são fundamentais para o desenvolvimento infantil, haja vista a maturação neurológica, formação de vínculo afetivo e a elaboração do conhecimento (VIANA, ANDRADE, LOPES, 2014). Os autores citados explanam que crianças com histórico de prematuridade estão sujeitas a apresentar alteração no desenvolvimento cognitivo e consequentemente na linguagem.

\subsection{Aquisição da Linguagem na perspectiva multimodal}

A aquisição da linguagem é um processo gradual que demanda algumas capacidades da criança e necessita de um ambiente favorável para que ocorra adequadamente. Essas capacidades são de ordem neurofisiológica e psicológica, sendo elas a percepção, memória, imitação e motricidade (ALVES et al, 2008). Durante os contextos interacionais, necessários para a aquisição e desenvolvimento da linguagem, os seres humanos utilizam diferentes ferramentas para se comunicar e produzir sentido. Dessa forma, as pesquisas científicas devem analisar a diversidade de maneiras pelas quais esse processo ocorre, que refletem comportamentos e estratégias dialógicas humanas (HAZEL, MONTENSEN, RASMUSSEN, 2014).

Enquanto objeto do conhecimento, a aquisição da linguagem é definida como o processo que ocorre desde um estado inicial no qual a criança não apresenta língua/linguagem ou um mecanismo estruturado de comunicação, expressão e interação social, e depois passa a dominar a língua da comunidade na qual está inserida, compartilhando a linguagem socialmente. Nesse sentido, o estudo da aquisição da linguagem busca explicar de que modo o ser humano parte de um estado no qual não possui qualquer forma de expressão verbal e de modo natural, sem a necessidade de instrução ou aprendizado formal, incorpora a língua de sua comunidade nos primeiros anos de vida, adquirindo um modo de expressão e de interação social dela dependente (CORREA, 1999).

A linguagem é um elemento fundamental para a vida em sociedade, estando relacionada ao modo como interagimos com nossos pares, refletindo padrões de comportamento apresentados socialmente (CUNHA, COSTA, MARTELOTTA, 2011). É através da mesma que a criança tem acesso a valores, crenças e regras, adquirindo elementos da cultura do ambiente em que vive, mesmo antes de falar. O surgimento da linguagem na criança, por mais que se desenvolva de modo natural dentro de sua comunidade, é um processo complexo que em um desenvolvimento típico requer a integridade de aspectos cognitivos, memória e componentes sensoriais, envolvendo múltiplas operações mentais.

Nos estudos linguísticos o termo multimodalidade é relativamente novo e refere-se às diversas modalidades de uso da língua, tanto a relação imagem/verbal quanto a relação gesto/fala (FONTE, CAVALCANTE, 2016). No contexto da teoria da multimodalidade na aquisição da linguagem, diversos autores trazem valiosas contribuições nas discussões realizadas na área, na sequência faremos uma breve revisão de aspectos relevantes abordados 
nas obras destes estudiosos de modo a apresentar algumas temáticas relativas à natureza do gesto e matriz gesto-fala.

O bebê inicia suas produções após a produção gestual da mãe, que funciona como incentivo inicial. Num segundo momento, conforme o desenvolvimento sensório-motor e o passar dos meses, a criança já se sente capaz de produzir seus próprios gestos sem que haja um incentivo inicial por parte da mãe. Nesse momento, é a criança que através de sua produção chamará a mãe para a interação. Apesar dessa iniciativa por parte da criança, a presença de um incentivo após a produção do bebê não deixa de existir e nem perde importância durante o processo de aquisição, pois é através dele que o bebê irá consolidar o gesto adquirido (CAVALCANTE, 2012).

O início da produção gestual e da produção vocal do bebê é caracterizado por movimentos desajeitados e desordenados e por sequencias sonoras repetidas sem conteúdo semântico explícito. A gesticulação e o balbucio do bebê no momento inicial da aquisição da linguagem sugerem que a matriz gesto-fala ainda não está estruturada, coordenada e ajustada para a significação da mensagem (FONTE et al., 2014).

Os gestos produzidos em situações interativas mãe-bebê, nos seus primeiros dezoito meses de vida são chamados hologestos. Os referidos gestos articulados com produção de fala em situações interativas diádicas (holófrases), permitem compreender a emergência da linguagem em aquisição a partir de um envelope multimodal que co-atuam em quatro planos: olhar, prosódia, gesto e produção verbal (CAVALCANTE, 2012).

Kendon (1988) em seus primeiros trabalhos defendia a concepção da integração existente entre gesto e fala, aspectos reafirmados e sistematizados por McNeill (1992), que considerava o gesto enquanto elemento linguístico e não como extralinguístico, estando gesto e fala integrados numa mesma matriz de produção e significação, compondo uma única matriz cognitiva, sendo portanto indissociáveis (CAVALCANTE, 2018). Os gestos propostos por Kendon (1982) estão presentes no momento de interação mãe-bebê, tanto a mãe quanto o bebê produzem gestos emblemáticos, gesticulação e pantomímicos. A gesticulação, consiste no primeiro tipo de gesto caracterizado pelo movimento de algumas partes do corpo do bebê, como por exemplo, a cabeça, as mãos e os braços, se inicia a partir dos 8 meses e é a partir deste primeiro gesto que a criança produzirá outros tipos de gestos. A pantomima é um gesto que se desenvolve especialmente dentro de contextos lúdicos, nos quais a mãe interage com o bebê através de brincadeiras e objetos. Esta produção costuma aparecer durante os nove meses de idade da criança e com doze meses o bebê já passa a realizar suas próprias pantomimas sem um incentivo inicial da mãe. Na aquisição da linguagem um dos gestos emblemáticos que mais se destaca é o apontar. Estes gestos (dar tchau, negativa manual e etc) não aparecem de forma definitiva na criança, se constituindo ao longo das interações (CAVALCANTE, 2012).

Tomasello (2008) postula a existência de uma infraestrutura cognitiva que possibilita a comunicação entre os seres humanos, a mesma estaria fundamentada no desenvolvimento da cooperação. Considera que os seres humanos primeiro desenvolveram a linguagem em gesto e posteriormente passaram a usar a fala, assumindo que os gestos de apontar e pantomimas teriam sido o primeiro meio pelo qual um vocabulário de expressões compartilhadas teria sido desenvolvido, constituindo assim a primeira forma de linguagem, e que os mesmos se constituíram como os elementos de transição no percurso evolutivo da comunicação humana e posterior criação de linguagens convencionais. O referido autor explana que o período linguístico se inicia apenas a partir do momento em que a criança apresenta uma estrutura sintática mínima, que a capacidade de cooperar em cenas de atenção conjunta é um aspecto diferencial dos seres humanos, como também que na situação comunicativa o que carrega o significado não é o contexto, mas a experiência compartilhada entre os participantes da interação, de modo que, para interpretar um gesto é necessário determinar qual a intenção do indivíduo ao dirigir a atenção para determinado ponto. 
Kendon (2008) faz uma crítica à noção de primazia do gesto defendida por Tomasello, como também a ideia que haveria um salto da produção gestual para a vocal, ao contrário, traz a hipótese que os extensos usos comunicativos da vocalização já devem estar em desenvolvimento por um período muito longo, estando a fala disponível e podendo-se prever a sua progressiva incorporação na função linguística. Assume que a transição para expressões referenciais ou semelhantes a idiomas envolve mãos, corpo, rosto, voz e boca atuando como um conjunto integrado. E que as expressões cinestésicas e audíveis estão tão intimamente entrelaçadas na criação de enunciados, de modo que a linguagem verbal nunca é falada apenas como palavras, estando a multimodalidade presente desde o início do processo.

Ávila-Nóbrega (2010) observa a emergência da língua em uma perspectiva multimodal em cenas de atenção conjunta envolvendo duas díades mãe-bebê, dos sete aos 17 meses de vida da criança. O envelope multimodal mescla três componentes da dialogia, sendo eles o olhar, o gesto e a produção vocal, implicando na análise de três ocorrências de ações em um mesmo momento, esses três planos de composição do envelope são as ações desempenhadas concomitantemente tanto pela mãe quanto pelo bebê. O olhar é classificado em Atenção de verificação, Atenção de acompanhamento e Atenção direta, conforme a teoria de Tomasello (2003). O gesto é classificado em gesticulação, emblema e pantomima, segundo Kendon (1982). E a produção vocal representa o último plano de análise. Os resultados apontam que a mãe faz uso do plano de composição multimodal para dirigir-se à criança, a qual interage conforme vai adquirindo os três componentes básicos da dialogia.

Baseadas em uma percepção de matriz gesto e fala, Cavalcante e Brandão (2012), a partir de estudos que analisaram os gestos na primeira infância em situações interativas diádicas, afirmam que os gestos atuam como co-partícipes do processo aquisicional, juntamente com a fala, uma vez que constituem a matriz da linguagem. Relatam ainda que não se deve restringir o processo aquisicional à produção verbal. Tal processo deve ser focado a partir de uma perspectiva multimodal onde diversos elementos se entrelaçam possibilitando que a criança se torne um falante da sua língua materna.

Cavalcante (1999), ao investigar a modalização vocal materna e o conjunto de modificações prosódico-afetivas da fala dirigida ao bebê, assume uma perspectiva interacionista para o fenômeno, concebendo a fala materna enquanto movimento interpretativo, principal responsável pela inserção da criança na língua. A autora considera que a mãe assume o bebê como um parceiro dialógico desde o início do seu desenvolvimento, de modo que a produção vocal e gestual do bebê é gerada nas situações linguísticas dialógicas com o adulto e se apoia num arcabouço gestuo-prosódico da língua, distanciando-se das concepções de primitivismo gestual e de continuidade estrutural entre gesto e a fala, postulando a perspectiva de não separação desses elementos (CAVALCANTE, 2018).

Nesse sentido, Barros (2012) se dedica ao estudo da prosódia, particularmente a entonação dentro do processo de aquisição da linguagem, caracterizando e mapeando o desenvolvimento entonacional de uma criança no período de $1 ; 0$ a 1;6 de vida, elaborando um contínuo tipológico vocal-prosódico, e assim permitindo uma caracterização das primeiras produções infantis como balbucio, jargão, holófrases e blocos de enunciado.

Barros e Cavalcante (2015), considerando que gesto e fala são indissociáveis, representando duas facetas de um único pensamento, demonstram como a prosódia e os gestos moldam a interação de uma criança com sua mãe desde o início do desenvolvimento linguístico, engajando a criança na interação e a guiando para a aquisição. Nessa perspectiva, são propostos os quatro momentos do funcionamento da fala na trajetória linguística infantil. A produção vocal inicial nesta trajetória é o balbucio, definido como a produção de sílabas muitas vezes repetitivas e ritmadas, que normalmente têm a estrutura consoante-vogal. Os jargões aparecem na fala infantil em torno dos 12 ou 13 meses de idade, são longas sequências de sílabas que contêm padrões de acento e entonação variados, parecendo enunciados completos que carregam 
conteúdo de afirmações ou perguntas. O terceiro momento do funcionamento da fala é o das primeiras palavras reconhecíveis, no qual são consideradas as produções contendo enunciados de uma palavra, sendo reconhecíveis na língua adulta e interpretáveis pelo interlocutor, indicam mudança nos contornos entoacionais reconhecidos como diferentes intenções comunicativas. O período de blocos de enunciado é definido como o momento em que a criança alterna a produção de holófrases com enunciados completos, a partir de um ano e meio a criança começa a utilizar os enunciados mais longos, já conseguindo fazer pedidos, perguntas e produzir respostas mais longas com significado completo.

Silva (2014) investiga a relação existente entre a emergência dos gestos, em especial da gesticulação, e as produções verbais, que juntos constituem a fluência multimodal no processo de aquisição da linguagem, entendida como a ocorrência concomitante de gestos e blocos enunciativos durante os momentos de interação. Para tal, foram realizadas gravações em situação naturalística de uma díade mãe-bebê, considerando a idade dos seis aos 24 meses de vida da criança e os dados foram divididos em três blocos de acordo com o período de tempo considerado. Observou-se que a gesticulação e a produção verbal estão constantemente sendo produzidas no período dos seis aos 24 meses de vida da criança, demonstrando que gestos e produção verbal compõem a fluência multimodal. Verificou-se que mesmo acontecendo pouca gesticulação, novos gestos sociais e culturais são adquiridos, como os gestos pantomímicos e emblemáticos. Como também, que não ocorre desaparecimento da gesticulação nem de todos os elementos prosódicos mencionados na tipologia, mas sim uma diminuição da sua ocorrência e um aumento de alguns gestos, como o emblemático e a pantomima. No que se refere à produção verbal, os blocos enunciativos também apresentam um aumento aos 24 meses.

A gestualidade é apontada como pista importante da fluência infantil, Cavalcante et al. (2015) destacam a relevância da matriz multimodal (gesto e fala) para a fluência em fase de aquisição da linguagem. Para os autores, a fluência é parte integrante do processo aquisicional e efetiva um discurso fluente através da atuação do gesto como co-partícipe da produção vocal.

A aquisição da linguagem deve ser entendida como um processo natural, que demanda uma serie de aspectos para que se desenvolva adequadamente, como o aparato neurocognitivo da criança, integridade dos componentes sensoriais e do aparelho fonador. Como também, a interação social é fundamental nesse processo, pois a criança desenvolve a linguagem nas relações dialógicas com o outro. Nesse processo de aquisição, as produções gestuais e vocais vão estruturando-se ao longo do tempo e de forma sincrônica gesto e fala tornam-se mais sofisticados e diversificados na trajetória linguística infantil (FONTE, 2014). Estudo refletiu sobre as primeiras interações entre mãe e bebê envolvendo o uso do gênero do discurso dentro da esfera familiar, mostrando como, a partir das estratégias de atenção conjunta, as rotinas interativas começam a se organizar em torno de gêneros orais diversos, como a conversa, o jogo, a história e as cantigas (CAVALCANTE, 2009).

Diante do exposto, verifica-se que a perspectiva multimodal traz valiosas contribuições para os estudos em aquisição, na medida em que se propõe a investigar aspectos da atenção conjunta, intencionalidade compartilhada, gestualidade, expressões faciais, elementos prosódicos, associados à produção da fala, desde o início do desenvolvimento infantil. A mesma considera que a comunicação humana se dá a partir da integração de diversos componentes, que na instância da matriz gesto-fala são indissociáveis entre si, essas produções estão mescladas na matriz da linguagem e apresentam valor fundamental na constituição do sujeito enquanto falante.

\subsection{Linguagem, multimodalidade e prematuridade}

A linguagem, nos domínios da linguagem compreensiva e expressiva (fala e gesto), consiste em um processo presente em crianças e que necessita de integridade sensorial, motora 
e cognitiva. No processo de desenvolvimento da linguagem infantil, diferentes gestos juntamente com as produções prosódico-vocais estão mesclados numa matriz única de significação - a matriz da linguagem (FONTE et al, 2014).

Um estudo analisou o desenvolvimento de linguagem em três grupos de idade gestacional: crianças extremamente prematuras (25-31 semanas de gestação, $n=204)$, prematuras moderadas tardias (32-33 semanas gestação e 34-36 semanas de gestação, $n=276$ ) e crianças nascidas a termo (37- 41 semanas de gestação, $n=268$ ). As habilidades de linguagem foram analisadas sequencialmente, a partir 5 meses de idade corrigida, até a idade cronológica de 8 anos. $O$ resultado da pesquisa mostrou que as crianças pré termo, mesmo prematuras moderadas tardias, tiveram pior desempenho na linguagem se comparadas às nascidas a termo. É importante ressaltar que as diferenças individuais no desempenho da linguagem estão cada vez mais estáveis a partir dos 20 meses a 8 anos em todos os grupos de gestação (PUTNICH et al., 2017).

As habilidades linguísticas envolvendo os aspectos fonológicos, lexicais, gramaticais e pragmáticos, como também habilidades cognitivas e memória em nascimento prematuro $(<32$ semanas) foram analisadas através de um estudo transversal com 60 crianças prematuras comparadas à 60 crianças com desenvolvimento típico. Demonstrou-se que as crianças prematuras apresentavam atrasos no léxico, nomeação e habilidades pragmáticas. Os atrasos na fonologia e na gramática foram menos difusos, envolvendo habilidades produtivas e foram dependentes das habilidades cognitivas e de memória (GUARINI et al., 2016). Portanto, crianças prematuras devem ser avaliadas com relação ao perfil linguístico objetivando o diagnóstico e intervenção precoce e assim a garantia do adequado desenvolvimento das habilidades linguísticas.

O desenvolvimento da linguagem dos prematuros é de bastante relevância em virtude dessas funções possibilitarem o desenvolvimento das habilidades de comunicação, socialização, afetivas, aprendizagem, dentre outras. Um estudo nessa perspectiva correlaciona os aspectos do desenvolvimento cognitivo e de linguagem em prematuros de 24 a 42 meses de idade cronológica (VIANA, ANDRADE, LOPES, 2014). O referido estudo explicitou que a prematuridade pode levar a alterações importantes nas etapas do desenvolvimento linguístico, em que a cognição se mostrou como fator primordial ao desenvolvimento das habilidades estudadas, constatando- se que, quanto maior a idade do desenvolvimento cognitivo, melhores são as habilidades de linguagem receptiva e expressiva.

$\mathrm{O}$ atraso e alterações no desenvolvimento da linguagem, prejuízos nos aspectos fonéticos e fonológicos, tais como inventário consonantal e a complexidade silábica destas crianças, podem estar relacionados ao nascimento prematuro e aos aspectos intrínsecos à prematuridade (RECHIA et al., 2016).

Cavalcante (2009), afirma que a multimodalidade pode ser entendida como a ocorrência de gestualidade concomitante às produções verbais (balbucio, variações prosódicas e holófrases), considerando que gesto e fala partem de uma mesma matriz de significação, formando um conjunto que não pode dissociar-se, tomando por base a concepção de que o funcionamento da língua é sempre multimodal.

Zampini e D'Odorico (2009) demonstraram em seu estudo que crianças com desenvolvimento atípico podem apresentar preferência pelo uso de produções gestuais e não verbais durante os primeiros estágios do desenvolvimento da linguagem. Os autores afirmam, ainda, que tais gestos são utilizados como tentativa de suprir as dificuldades de expressão oral próprias desta população e que à medida que esta vai se desenvolvendo o uso dos gestos comunicativos diminuem, concedendo um maior espaço para habilidades expressivas orais.

Cattani et al. (2010) observaram o desenvolvimento comunicativo e linguístico durante o segundo ano de vida em um grupo de doze crianças italianas nascidas prematuramente, com o objetivo principal de comparar a produção de ação / gesto, 
compreensão e produção de palavras, e a relação entre esses três domínios em crianças prematuras e dados normativos obtidos de uma grande amostra de 59 crianças italianas nascidas a termo, como também discutir sobre o uso da idade gestacional cronológica versus corrigida na avaliação de habilidades das crianças prematuras. Como resultados, as crianças prematuras apresentaram atraso nos três aspectos da comunicação e da linguagem. Em particular, a idade linguístico-comunicativa tendeu a ficar aproximadamente 3 meses atrás da idade cronológica quando as crianças tinham entre 12 e 24 meses de idade. Quando a idade cronológica foi usada, os escores percentuais das crianças prematuras para os três componentes da comunicação e da linguagem caíram dentro dos limites mais baixos, enquanto as pontuações calculadas com a idade corrigida caíam no percentil 50 ou acima dele. Os resultados sugerem que, apesar do risco biológico significativo gerado pelo nascimento prematuro, o desenvolvimento comunicativo e linguístico inicial parece ocorrer de maneira relativamente robusta entre crianças prematuras, com relações estreitas entre domínios comunicativos, como em crianças a termo. Empregando ambos critérios cronológicos e de idade gestacional corrigidos na avaliação das habilidades de prematuros podem fornecer informações importantes sobre seu progresso na aquisição de linguagem.

Sansavini et al. (2011) realizaram uma análise longitudinal através da comparação de vinte bebês a termo com cento e quatro bebês prematuros, sendo observado os gestos/ações, compreensão e produção verbal. Os prematuros apresentaram uma aquisição mais lenta na produção de gestos / ações, compreensão e produção de palavras com uma divergência crescente em relação aos termos. As competências lexicais aos 12 meses e os gestos / ações aos 18 meses foram preditivos de produção de palavras aos 24 meses, com uma contribuição mais forte da compreensão de palavras aos 12 meses e da produção de palavras aos 18 meses. Tais achados revelam um ritmo mais lento de desenvolvimento linguístico-comunicativo em muitos prematuros, com uma diferença crescente em suas competências gestuais e lexicais no segundo ano de vida em relação aos termos completos.

Sansavini et al. (2015) avaliaram a compreensão e produção lexical, bem como produção gestual em crianças prematuras com idade gestacional extremamente baixa, concentrando-se na aquisição de substantivos e predicados. Quarenta crianças prematuras e quarenta crianças a termo foram avaliadas aos dois anos de idade cronológica corrigida usando um teste de compreensão e produção de substantivos e predicados. A compreensão e produção de substantivos foi atrasada nos prematuros em comparação com as crianças nascidas a termo, observado pelo baixo número de respostas corretas e pelo grande número de erros. Em relação à compreensão e produção de predicados, uma maior frequência de ausência de respostas foi relatada por crianças prematuras e essas crianças também apresentaram menor frequência de respostas bimodais envolvendo gesto e fala na produção de predicados do que crianças nascidas a termo. Os resultados revelaram que o conhecimento era transmitido com menos frequência através da modalidade gestual falada bimodal em crianças prematuras. Em relação aos gestos, menos gestos representacionais foram produzidos por crianças prematuras no subteste de produção de predicado (ou seja, em ações de nomeação e propriedades do objeto). O menor uso de respostas gestuais e faladas para predicados exibidos por crianças prematuras com 2;0 demonstra que essas crianças são menos capazes de recorrer a combinações falado-gestuais para expressar significados, podendo estar associado a fatores motores, cognitivos e linguísticos. As modalidades falada unimodal e falada / gestual bimodal foram empregadas principalmente por ambas as amostras, considerando que a modalidade gestual unimodal era rara porque ambas as amostras exibiam audição normal e foram expostas a estímulos desde o nascimento. Gestos dêiticos, que ajudam as crianças a compartilhar um referente com o adulto e manter sua atenção ao referente, associaram-se à fala nas crianças pertencentes às duas amostras para identificar o referente. 
Estudo investigou o valor preditivo entre o desenvolvimento de gestos iniciais e léxico receptivo mensurados entre as idades de 0:9 e 1:3, e o valor preditivo da capacidade de linguagem receptiva e expressiva aos 2:0 para habilidades de linguagem aos 5:0, por meio de um acompanhamento longitudinal de 29 crianças prematuras com muito baixo peso ao nascer e 28 crianças nascidas a termo. Em crianças prematuras com muito baixo peso, o desenvolvimento de gestos, medido entre $0 ; 9$ e $1 ; 3$, mostrou correlação significativa e positiva com as habilidades de linguagem apresentadas aos 5;0 de idade. Além disso, a capacidade de linguagem receptiva e expressiva, medida aos $2 ; 0$ de idade, correlacionou-se significativa e positivamente com as habilidades linguísticas posteriores nos dois grupos. De acordo com a análise de regressão hierárquica, o escore de linguagem receptiva mensurado aos 2;0 foi um preditor claro e significativo para habilidades de linguagem aos 5; 0 em ambos os grupos. Os resultados fornecem evidências de uma continuidade entre os primeiros desenvolvimentos da linguagem e habilidades linguísticas posteriores, podendo-se destacar o papel dos gestos como um preditor significativo para habilidades de linguagem em crianças prematuras (STOLT et al., 2016).

Zuccarini et al (2018) examinaram as relações entre comportamentos exploratórios ativos aos 6 meses e 12 meses com a compreensão de palavras, gestos e produção vocal, controlando o desenvolvimento cognitivo e condição neonatal. Participaram quarenta crianças, 20 com idade gestacional extremamente baixa ( $<28$ semanas) e 20 nascidas a termo, e suas mães, com gravações em vídeo da interação em um jogo. A exploração oral e manual de objetos aos 6 meses e gestos espontâneos e produção vocal aos 12 meses foram avaliadas, as análises de regressão mostraram que a exploração oral estava relacionada à compreensão de palavras, e a exploração manual se relacionava aos gestos e à produção vocal na amostra geral. Considerando que as habilidades motoras desempenham um papel importante no desenvolvimento da linguagem, e que os bebês prematuros apresentam maior risco de atrasos motores e de linguagem do que bebês a termo, revela-se a importância da exploração de objetos para o desenvolvimento linguístico posterior, favorecendo a emergência de gestos, produção e compreensão de palavras.

Pesquisa longitudinal investigou o desenvolvimento do gesto comunicativo em 16 crianças prematuras e 31 crianças nascidas a termo, aos 12, 18 e 24 meses de idade. Os gestos comunicativos espontâneos foram analisados durante as sessões de observação mãe-filho. $\mathrm{O}$ desenvolvimento motor, cognitivo e linguístico das crianças prematuras também foi mensurado. O desenvolvimento da comunicação gestual não diferiu significativamente entre os grupos, exceto pelo uso de combinações de gesto com palavra aos 18 e 24 meses, quando as crianças nascidas a termo produziram significativamente mais combinações do que as crianças prematuras. Para crianças prematuras, o gesto de apontar aos 12 meses associou-se positivamente ao desenvolvimento de habilidades lexicais aos 24 meses, assim como o uso de expressões com gestos mais palavras aos 18 meses estimulou habilidades morfossintáticas aos 24 meses. Outras análises considerando um subgrupo de crianças prematuras caracterizadas por baixo peso ao nascer e seus escores mentais, demonstraram aumento duradouro na produção de gestos comunicativos ao longo do tempo, perfil que pode ser associado a atrasos posteriores na aquisição do idioma, com dificuldades no surgimento de habilidades verbais tipicamente esperadas (SUTTORA, SALERNI, 2012).

A qualidade da interação mãe-bebê prematuro é identificada como um fator importante para influenciar o desenvolvimento posterior da criança e aquisição da linguagem. Nesse sentido, estudo descreveu a relação entre a capacidade de resposta diádica mútua mãe-bebê e o desenvolvimento prematuro do bebê, considerando bebês prematuros nascidos entre 29 e 34 semanas de idade gestacional e suas mães que tinham condições de riscos socioambientais. Com 6 semanas de idade corrigida, uma sessão de brincadeiras foi registrada para a análise qualidade da capacidade de resposta mútua. $\mathrm{O}$ desenvolvimento foi avaliado através de uma 
escala de desenvolvimento infantil. Das 137 díades mãe-bebê, observou-se alta, média e baixa responsividade mútua em $35,8 \%, 34,3 \%$ e $29,9 \%$, respectivamente. Os escores motores, de linguagem e cognitivos foram de $115,8(\mathrm{DP}=8,2), 108,0(7,7)$ e 109,3 $(7,9)$. Comparando bebês em díades com alta versus baixa responsividade mútua, os bebês com alta responsividade apresentaram escores mais altos nas escalas motora e linguagem. A alta capacidade de resposta mútua nas díades mãe-bebê prematuro está associada a uma melhora significativa no desenvolvimento da linguagem e melhor desenvolvimento motor (WHITE-TRAUT et al., 2018).

$\mathrm{O}$ atraso na linguagem é um problema bem documentado que ocorre em uma taxa mais alta em crianças prematuras em comparação com bebês nascidos a termo. As habilidades sociais desenvolvidas precocemente antes da emissão dos primeiros vocábulos, como a capacidade de compartilhar a atenção de um objeto com outra pessoa (interação triádica), são sugeridas para refletir parte dos processos pelos quais as crianças aprendem a língua. Nesse sentido, estudo longitudinal examinou habilidades linguísticas em 25 crianças prematuras e 35 nascidas a termo para investigar se o status do nascimento afeta o desenvolvimento da linguagem através dos processos de mediação de habilidades diádicas e triádicas. Também foram avaliadas aos 6 meses as iniciativas diádicas durante o "still-face", tarefa em que ocorre uma interação face a face na qual a mãe apresenta expressões faciais não responsivas às iniciativas do bebê. A resposta triádica (seguimento do olhar) foi examinada aos 9 e 14 meses, iniciativas triádicas (atenção conjunta e solicitação comportamental) também foram avaliados aos 14 meses, as linguagens receptiva e expressiva foram examinadas aos 30 meses. Os dados mostraram diferenças de grupo em iniciativas diádicas de 6 meses, capacidade de resposta triádicas aos 9 meses, iniciativas comportamentais triádicas de 14 meses, e respostas nas habilidades de linguagem receptivas e expressivas de 30 meses nas crianças prematuras, confirmando o risco de desenvolvimento linguístico menos favorável (SCHUYMER et al., 2011).

Pesquisa realizada no Brasil comparou a evolução das vocalizações em bebês prematuros e a termo, com e sem risco de desenvolvimento, analisando as possíveis associações existentes com variáveis sociodemográficas, obstétricas e psicossociais. Participaram 30 crianças, com idade entre 3 meses e 1 dia a 4 meses e 29 dias (Fase 1) e 6 meses e 1 dia a 7 meses e 29 dias (Fase 2), de ambos os sexos, com idade gestacional $<37$ semanas (grupo prétermo) e $>37$ semanas (grupo a termo). Foram utilizados os instrumentos: Indicadores de Risco de Desenvolvimento Infantil (IRD1), o Teste Denver II, uma entrevista sobre a experiência de maternidade com dados sociodemográficos, obstétricos e psicossociais, bem como filmagens da díade mãe-bebê nas duas fases da pesquisa. As filmagens foram analisadas usando o software EUDICO Linguistic Annotator (ELAN). Identificou-se que, quanto mais Indicadores de Risco ao Desenvolvimento Infantil presentes, maior foi o número total de vocalizações do bebê, assim como aumentou a frequência de vocalizações das mães com manhês. Também se percebeu aumento significativo de vocalizações sem manhês na fase 2 pesquisada. As variáveis sociodemográficas, idade gestacional, peso ao nascer, escolaridade materna e o Critério Brasil não incidiram diretamente no nível de vocalizações dos bebês. A análise das vocalizações dos bebês associou-se ao risco ao desenvolvimento, assim como os Indicadores de Risco ao Desenvolvimento Infantil, na fase 1 pesquisada, o teste Denver-Linguagem é mais efetivo na fase 2. Não houve influência das variáveis sociodemográficas na fase estudada (FATTORE et al., 2017).

Diante do exposto, percebe-se a relação existente entre aquisição da linguagem e multimodalidade em crianças prematuras. Ressalta-se a importância do acompanhamento linguístico dessas crianças nos primeiros anos de vida, objetivando diagnóstico e intervenção precoce para favorecer a comunicação e socialização dessa população, como também a relevância dos estudos em multimodalidade voltados para essa população, considerando as 
Volume 14 - Número 2 - ago/dez de 2019

múltiplas possibilidades de expressão comunicativa que se apresentam no processo de aquisição desde a mais tenra idade e assumindo a indissociabilidade envolvida na matriz gesto-fala.

\section{Considerações finais}

Nas bases de dados pesquisadas foi observada a escassez de estudos que discutissem o desempenho linguístico de crianças prematuras, a partir da multimodalidade. Dentre as contribuições apresentadas nos estudos analisados, os mesmos demonstraram que as crianças nascidas mais precocemente tiveram um desempenho pior na linguagem do que as prematuras moderadas e tardias, além de lenta aquisição na produção de gestos, atrasos no léxico, pragmática, sendo os atrasos na fonologia e gramática menos difusos, corroborando com as discussões que a prematuridade, associada a aspectos cognitivos, pode levar a alterações importantes nas etapas do desenvolvimento linguístico. Os prematuros apresentaram uma aquisição mais lenta na produção de gestos/ações, compreensão e produção de palavras, sendo que o conhecimento era transmitido com menos frequência através da modalidade gestual falada bimodal nestas crianças. Podendo-se destacar também o papel dos gestos como um preditor significativo para habilidades de linguagem em crianças prematuras, associando-se positivamente ao desenvolvimento de habilidades lexicais e morfossintáticas. Em bebês prematuros, observou-se um risco de desenvolvimento linguístico menos favorável, a análise das vocalizações dos bebês associou-se ao risco ao desenvolvimento, como também a interação com alta capacidade de resposta mútua nas díades mãe-bebê prematuro está associada a uma melhora significativa no desenvolvimento da linguagem.

Sugere-se mais estudos voltados para os aspectos multimodais e linguísticos da referida população, beneficiando o entendimento de como eles se revelam ou, até mesmo, de como podem ser criadas estratégias de ampliação da comunicação, considerando os variados contextos de circulação da Língua com vistas à interação.

\section{Referências}

ALMEIDA, A. C.; JESUS, A. C. P.; LIMA, P. F. T.; ARAÚJO, M. F. M.; ARAÚJO, T. M. Fatores de risco maternos para prematuridade em uma maternidade pública de Imperatriz MA. Revista Gaúcha Enfermagem, Porto Alegre (RS), v. 33, n.2, p. 86-94, 2012.

Disponível em: http://www.scielo.br/pdf/rgenf/v33n2/13. Acesso em 01 de junho de 2019. ALVES, G. A. S.; DELGADO, I. C.; VASCONCELOS, M. L. O desenvolvimento da linguagem escrita em crianças com Síndrome de Down. Revista Prolíngua, João Pessoa, v.1, n.1, p.48-55, 2008.

ÁVILA-NÓBREGA, P. V. Dialogia mãe-bebê: a emergência do envelope multimodal em cenas de atenção conjunta. 2010. 165f. Dissertação (Mestrado em Linguística) - Universidade Federal da Paraíba, João Pessoa.

BARROS, A. T. M. de C. Fala inicial e prosódia: do balbucio aos blocos de enunciados. 2012. 180 f. Dissertação (Mestrado em Linguística) - Universidade Federal da Paraíba, João Pessoa.

BARROS, A. T. M. C.; CAVALCANTE, M. C. B. Prosódia e gestos: caracterizando a matriz multimodal nas interações adulto-criança. In: CAVALCANTE, M. C. B.; FARIA, E. M. B. (Orgs.). Cenas em aquisição da linguagem: multimodalidade, atenção conjunta e subjetividade. 1 ed. João Pessoa: Editora da UFPB, 2015. c. 2, p. 45-64.

BRASIL. Ministério da saúde. Atenção à saúde do recém- nascido: guia para profissionais da saúde: Cuidados com o recém-nascido pré termo. 2 ed. Brasília, Distrito Federal, 2011. 
CATTANI, A.; BONIFACIO, S.; FERTZ, M.; IVERSON, J. M.; ZOCCONI, E.; CASELLIK, M. C. Communicative and linguistic development in preterm children: a longitudinal study from 12 to 24 months. Int. J. Lang. Comm. Dis., v. 45, n. 2, p. 162-173, 2010.

CAVALCANTE, M. C. B. Da voz à língua: a prosódia materna e o deslocamento do sujeito na fala dirigida ao bebê. 1999. 240f. Tese (Doutorado em Linguística) - Instituto de Estudos da Linguagem, Universidade Estadual de Campinas, Campinas.

CAVALCANTE, M. C. B. Contribuições dos estudos gestuais para as pesquisas em aquisição da linguagem. Linguagem \& Ensino, Pelotas, v.21, n. esp., p. 5-35, 2018.

CAVALCANTE, M. Rotinas interativas mãe- bebê: constituindo gêneros do discurso.

Investigações (Recife), v. 21, p. 153-170, 2009.

CAVALCANTE, M. C. B. Hologestos: Produções Linguísticas numa perspectiva multimodal.

Revista de Letras, n. 31, v. 1/2, 2012.

CAVALCANTE, M; BARROS, A; SILVA, P; ÁVILA-NÓBREGA, P. Gestualidade como pista importante da fluência infantil. Revista prolíngua. v.10. n.1, p.43-50, 2015.

CAVALCANTE, M; BRANDÃO, L. Gesticulação e Fluência: Contribuições para a aquisição da linguagem. Caderno de estudos linguísticos. v. 54, n.1, p. 55-66, 2012.

CORREA, L. M. S. Aquisição da Linguagem: Uma Retrospectiva dos Últimos Trinta Anos. DELTA, v. 15, n. esp., 1999.

CUNHA, A.; COSTA, M.; MARTELOTTA, M. Linguística. In: MARTELOTTA, M. (Org.). Manual de linguística. São Paulo: Contexto, 2011.

FATTORE, I. M.; UHDE, R. M.; OLIVEIRA, L. D.; ROTH, A. M.; SOUZA, A. P. R.

Comparative analysis of initial vocalizations of preterm and full-term infants with and without risk for development. CoDAS, v. 29, n. 4, p. 1-9, 2017.

FONTE, R.; BARROS, A. CAVALVANTE, M.; SOARES, P.M. A Matriz Gesto- fala na aquisição da linguagem: algumas reflexões. In: BARROS E Orgs. Aquisição, Desvios e Práticas de Linguagem. 1 ed. Curitiba: editora CRV, 2014, Pag. 11-26.

FONTE, R. F. L. da; CAVAlCANTE, M. C. B. Abordagem multimodal da linguagem: contribuições à clínica fonoaudiológica. In: Ana Cristina de Albuquerque Montenegro; Isabela Barbosa do Rêgo Barros; Nadia Pereira da Silva Gonçalves de Azevedo. (Org.). Fonoaudiologia e Linguística: teoria e prática. Curitiba: Appris, 2016, v. 1, p. 205-205.

GUARINI, A.; MARINI, A.; SAVINI, S.; ALESSANDRONI, R.; FALDELLA, G.; SANSAVINI, A. Características linguísticas em crianças nascidas muito prematuras em idade escolar. Developmental Medicine e Child Neurology, 2016. Disponível em: https://onlinelibrary.wiley.com/doi/full/10.1111/dmen.13118. Acesso em 06 de junho de 2019 HAZEL, S.; MONTENSEN, K.; RASMUSSEN, G. Introduction: a body of resources - CA studies of social conduct. Journal of Pragmatics, v.65, p.1-9, 2014.

KENDON, A. The Study of Gesture: some remarkson its history. Recherches sémiotiques/ semioticinquiry, v. 2, p. 45-62, 1982.

KENDON, A. How gestures can become like words. Crosscultural Perspectives in

Nonverbal Communication, (January), p. 131-141, 1988.

KENDON, A. Language's matrix. Gesture. v. 9, p. 355-372, 2008.

LORANDI, A.; CRUZ, C. R.; SCHERER, A. P. R. Aquisição da linguagem. Verba Volant, v. 2, n. 1, p. 144-166. Pelotas: Editora e Gráfica Universitária da UFPel, 2011.

MCNEILL, D. Hand and Mind. What Gestures Reveal about Thought. Chicago: University of Chicago Press, 1992.

MELLO, R; MEIO, M. Follow-up de Recém-Nascido de Risco. In: MOREIRA, M; BRAGA, N; MORSCH, D. Quando a vida começa diferente: o bebê e sua família na UTI neonatal.

Rio de Janeiro: Fiocruz, 2003.

MELLO, R.R. REIS, A.B.R.; SILVA, K.S. Desempenho cognitivo de prematuros: associação entre displasia broncopulmonar e habilidades cognitivas. Estudo transversal. Revista Médica 
Volume 14 - Número 2 - ago/dez de 2019

de São Paulo. v. 135, n. 4, 2017. Disponível em: http://dx.doi.org/10.1590/15163180.2017.0010190317. Acesso em 01 de junho de 2019.

ORGANIZAÇÃO MUNDIAL DE SAÚDE. Nascimento prematuro. Genebra; 2013.

Disponível em: http://www.who.int/mediacentre/factsheets/fs363/en/index.html. Acesso em 17 de outubro de 2019.

PESSOA, T. A. O.; LIMA, F.C.A.; MARTINS, C.B.G.; GAIVA, M.A.M. O crescimento e desenvolvimento frente à prematuridade e baixo peso ao nascer. Av Enferm. v. 133, n. 3, p. 401-411, 2015. Disponível em: http://www.scielo.org.co/pdf/aven/v33n3/v33n3a08.pdf. Acesso em 06 de junho de 2019.

PUTNICK, D. L.; BORNSTEIN, M. H.; ERYIGIT-MADZWAMUSE, S.; WOLKE, D. Longterm stability of language performance in very preterm, moderate-late preterm, and term children. The Journal of Pediatrics, v. 181, p. 74-79, 2017. Disponível em:

https://www.jpeds.com/article/S0022-3476(16)30916-7/pdf. Acesso em 07 de junho de 2019. RAMOS, H. A. C.; CUMAN, R.K.N. Fatores de risco para prematuridade: pesquisa documental. Esc. Anna Nery Revista de enfermagem, v. 13, n. 2, p. 297-304, 2009. Disponível em: http://www.scielo.br/pdf/ean/v13n2/v13n2a09. Acesso em 06 de junho de 2019.

RECHIA, I. C.; OLIVEIRA, L. D.; CRESTANI, A.H.; BIAGGIO, E. P. V.; SOUZA, A. P. R. Efeitos da prematuridade na aquisição da linguagem e na maturação auditiva: revisão sistemática. Codas, v. 28, n. 6, p. 843-854, 2016. Disponível em:

http://www.scielo.br/scielo.php?pid=S231717822016000600843\&script=sci_abstract\&tlng=p t. Acesso em 02 de junho de 2018.

SANSAVINI, A et al. Longitudinal trajectories of gestural and linguistic abilities in very preterm infants in the second year of life. Neuropsychol. v. 49, n. 13, p. 3677-88, 2011. SANSAVINI, A.; BELLO, A.; GUARINI, A.; SAVINI, S.; ALESSANDRONI, R.; FALDELLA, G.; CASELLI, C. Noun and predicate comprehension/production and gestures in extremely preterm children at two years of age: Are they delayed? Journal of Communication Disorders, v. 58, p. 126-142, 2015.

SCHUYMER, L.; GROOTE, I.; BEYERS, W.; STRIANO, T.; ROEYERS, H. Preverbal skills as mediators for language outcome in preterm and full term children. Early Human Development, v. 87, p. 265-272, 2011.

SILVA, P. M. S. Gestos e produção verbal: a fluência multimodal em aquisição da linguagem. 2014. 98f. Dissertação (Mestrado em Linguística) - Universidade Federal da Paraíba.

STOLT, S.; LIND, A.; MATOMAKI, J.; HAATAJA, L.; LAPINLEIMU, H.; LEHTONEN, L. Do the early development of gestures and receptive and expressive language predict language skills at 5;0 in prematurely born very-low-birth-weight children?. Journal of Communication Disorders. v. 61, p. 16-28, 2016.

SUTTORA, C.; SALERNI, N. Gestural development and its relation to language acquisition in very preterm children. Infant Behavior \& Development, v. 35, p. 429-438, 2012. TOMASELLO, M. Origens Culturais do Conhecimento Humano. São Paulo: Martins Fontes, 2003.

TOMASELLO, M. A Focus on Infrastructure. In: TOMASELLO, M. Origins of human communication. Cambridge: The MIT Press. A Bradford Book., 2008. c. 1, p. 1-12. VALÉRIO, G.; GARDENGHI, G. Atualização em displasia broncopulmonar. Revista Eletrônica Saúde e Ciência- RESC, v. 6, n. 1, p.45-53, 2016. Disponível em: https://www.rescceafi.com.br/vol6/n1/artigo05-45a53.pdf. Acesso em 07 de junho de 2019. VIANA, T.P.; ANDRADE, I.S.N.; LOPES, A.N.M. Desenvolvimento cognitivo e linguagem em prematuros. Audiology - Communication Research, v. 19, n. 1, p.1-6, 2014. Disponível 
Volume 14 - Número 2 - ago/dez de 2019

em: http://www.scielo.br/pdf/acr/v19n1/2317-6431-acr-19-1-0001.pdf. Acesso em 02 de junho de 2019.

WHITE-TRAUT, R. C.; RANKINC, K. M.; YODERA, J.; ZAWACKID, L.; CAMPBELLE, S.; CENSULLOF, M.; KAVANAUGHB, K.; NORRA, K. F. Relationship between motherinfant mutual dyadic responsiveness and premature infant development as measured by the Bayley III at 6 weeks corrected age. Early Human Development, v. 121, p. 21-26, 2018. ZAMPINI L, D'ODORICO L. Communicative gestures and vocabulary development in 36month-old children with Down's syndrome. Int J Lang Comm Dis. v. 44, n. 6, p. 1063-73, 2009.

ZUCCARINI, M.; GUARINI, A.; IVERSON, M.; BENASSI, E.; SAVINI, S.;

ALESSANDRONI, R.; FALDELLA, G.; SANSAVINI, A. Does early object exploration support gesture and language development in extremely preterm infants and full-term infants? Journal of Communication Disorders, v. 76, p. 91-100, 2018. 